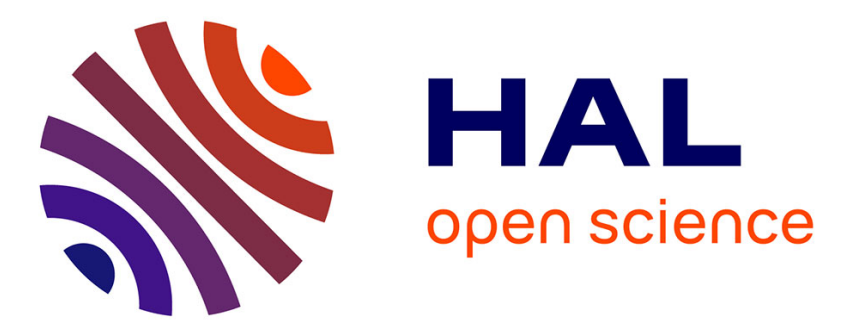

\title{
Emergence patterns of novelty in European vegetation assemblages over the past 15000 years
} Walter Finsinger, Thomas Giesecke, Simon Brewer, Michelle Leydet

\section{To cite this version:}

Walter Finsinger, Thomas Giesecke, Simon Brewer, Michelle Leydet. Emergence patterns of novelty in European vegetation assemblages over the past 15000 years. Ecology Letters, 2017, 20 (3), pp.336-346. 10.1111/ele.12731 . hal-01681566

\section{HAL Id: hal-01681566 https://hal.science/hal-01681566}

Submitted on 7 May 2018

HAL is a multi-disciplinary open access archive for the deposit and dissemination of scientific research documents, whether they are published or not. The documents may come from teaching and research institutions in France or abroad, or from public or private research centers.
L'archive ouverte pluridisciplinaire HAL, est destinée au dépôt et à la diffusion de documents scientifiques de niveau recherche, publiés ou non, émanant des établissements d'enseignement et de recherche français ou étrangers, des laboratoires publics ou privés. 


\section{Emergence patterns of novelty in European vegetation assemblages over the past 15000 years}

Walter Finsinger, ${ }^{1 *} \quad$ Thomas Giesecke, ${ }^{2}$ Simon Brewer ${ }^{3}$ and Michelle Leydet ${ }^{4}$

\begin{abstract}
Plant communities are not stable over time and biological novelty is predicted to emerge due to climate change, the introduction of exotic species and land-use change. However, the rate at which this novelty may arise over longer time periods has so far received little attention. We reconstruct the emergence of novelty in Europe for a set of baseline conditions over the past 15000 years to assess past rates of emergence and investigate underlying causes. The emergence of novelty is baseline specific and, during the early-Holocene, was mitigated by the rapid spread of plant taxa. Although novelty generally increases as a function of time, climate and human-induced landscape changes contributed to a non-linear post-glacial trajectory of novelty with jumps corresponding to periods of rapid changes. Emergence of novelty accelerated during the past 1000 years. Historical cultural landscapes experienced a faster novelty development due to the contribution from anthropogenic land-cover changes.
\end{abstract}

\section{Keywords}

Biological novelty, EPD, Europe, pollen, post-glacial.

\section{INTRODUCTION}

The inevitable consequence of individualistic changes in species distributions (Gleason 1939) is that modern associations will be reshuffled into substantially different associations with respect to historical and present baseline conditions (Hobbs et al. 2009, 2014) through several mechanisms. Parts of the modern climate space may disappear and currently unavailable portions of the climate space may unfold, thereby potentially restricting suitable habitats for species lacking a pre-adaptation to abiotic novelty in climate conditions (Williams \& Jackson 2007; Reu et al. 2014; Ordonez et al. 2016). Rapid rates of climate change could cause biological novelty, if suitable climate space shifts across the landscape faster than species dispersal velocity (Jackson \& Overpeck 2000; Ordonez et al. 2016). Rates of change in radiative forcing by greenhouse gases during the 20th century already have exceeded any rates sustained during the past 22000 years (Joos \& Spahni 2008) and rates of climate change are predicted to exceed those experienced by ecosystems during the past 20000 years (Diffenbaugh \& Field 2013). In addition to the effects of climate change, human agency is considered the major driver of the rise of novelty today (Radeloff et al. 2015) due to widespread landscape management, the spread of alien invasive species, and land-use.

Vegetation models can be used to predict the emergence of biotic novelty (Reu et al. 2014). However, the predictive power of vegetation models to forecast the reshuffling of species into novel associations in future novel climate combinations may be rather limited (Williams \& Jackson 2007). Whether or not climate change propagates into the recombination of species may depend on the extent of their fundamental niches rather than on their modern realized niches, which are at the basis of most vegetation models (Reu et al. 2014). This difference between modern realized and fundamental niches might arise from the different climate space available at present-day, and from the effects of competition among species and actual disturbance regimes (Jackson \& Overpeck 2000). Additionally, in some parts of the species' range populations were favoured or became locally extinct due to land-use pressure and anthropogenic disturbance (Bradshaw \& Lindbladh 2005; Tinner et al. 2013). Further, vegetation models are constrained by a limited set of environmental variables, and the effects of, for example, land-use changes and disturbances by wildfires are not fully implemented (Reu et al. 2014; Radeloff et al. 2015).

The large majority of studies attempting to reconstruct the emergence of novelty are limited to relatively short time periods, typically no longer than a few centuries from past baselines to the present (Hobbs et al. 2009; Radeloff et al. 2015). Therefore, the long-term dynamics of emergence of biotic novelty and the relationships to rates of environmental change are largely unknown. However, understanding the dynamics of novelty emergence has fundamental implications for ecology, evolution and conservation (Jackson \& Overpeck 2000; Jackson \& Williams 2004), as it relates to the broader question of whether species associations persist over time or are ephemeral. Several open questions were recently discussed by

\footnotetext{
${ }^{1}$ Palaeoecology, ISE-M (UMR 5554 CNRS/UMIEPHE), Place E. Bataillon, 34095 Montpellier, France

${ }^{2}$ Department of Palynology and Climate Dynamics, Albrecht-von-Haller-Institute for Plant Sciences, University of Göttingen, Untere Karspüle 2, 37073 Göttingen, Germany
}

\author{
${ }^{3}$ Geography Department, University of Utah, 260 S. Central Campus Drive, \\ Salt Lake City, UT 84119, USA \\ ${ }^{4} I M B E-C N R S$, Aix-Marseille Université, IRD, Avignon Université, Technopôle Arbois- \\ Méditerranée, Bât. Villemin-BP 80, F-13545 Aix-en-Provence Cedex 04, France \\ *Correspondence: E-mail: walter.finsinger@um2.fr
}


Jackson (2013) including: does novelty always increase as a linear (or curvilinear) function of time from the observer, such that novelty is always high far in the future? Is novelty related to rates of environmental changes, such that it rises at times of high rates of environmental change? Can human agency accelerate the processes that lead to the rise of novelty?

Pollen records document vegetation composition changes on centennial to millennial timescales. These archival records suggest that ecological change is a key feature in a world of continual environmental flux (Jackson \& Overpeck 2000) and palaeoenvironmental databases (Brewer et al. 2016) shed light on the dynamics of vegetation change at subcontinental scales (Huntley \& Birks 1983; Williams et al. 2013). The pattern of European land-cover change is increasingly well documented by fossil pollen records (Brewer et al. 2016) and the representation is being refined using quantitative assessments (Gaillard et al. 2010). These pollen records demonstrate that late-glacial to early-Holocene climatic changes triggered the spread and expansion of plant populations (Birks \& Ammann 2000; Williams et al. 2002). The clearance of European forests for agriculture, fuel and industrial resources started during the mid-Holocene and progressed over millennia (Fyfe et al. 2015), reaching the lowest tree cover during the 18th century (Millennium Ecosystem Assessment 2005). Factors that are expected to cause a rise of biological novelty in the future have also acted in the past. For example, the high within-site rates of vegetation change (RoC) associated to the post-glacial spread of plants and to past anthropogenic land-cover changes (Huntley 1990; Seddon et al. 2015), often coupled to the spread of agriculture may be compared to the currently observed spread of alien species and land-use changes. Based on this, we use the fossil record to investigate the long-term temporal and spatial patterns of emergence of novelty and its relations with RoC.

The degree of dissimilarity between contemporary and fossil pollen assemblages has been extensively investigated for a number of regions (Overpeck et al. 1985; Huntley 1990; Bush et al. 2004). Many of these studies revealed the past occurrence of pollen assemblages without close modern counterparts ('no-modern analogues'), thereby supporting Gleason's (1939) inferences on the individualistic range dynamics (Matthews 1996) and replacing, as previously suggested (Davis 1981), the static view of coevolved plant communities.

But, rather than looking into the past with the eyes of a modern observer, here, we look forward from the past to reconstruct the long-term emergence of novelty, enabling comparisons between past and recent rates of novelty emergence. Given the presumed relationships between rates of environmental change and novelty (Jackson \& Overpeck 2000; Radeloff et al. 2015), we expect that the rate at which novelty arises is faster at times of rapid environmental changes, such as those characterizing the late-glacial to interglacial transition and the late-Holocene anthropogenic land-cover changes, which led to high rates of vegetation change (RoC) (Huntley 1990; Seddon et al. 2015). Smaller amplitude Holocene climate variations (NGRIP Members 2004) and the more gradual and site-specific impact of earlier human-induced landscape changes are expected to have given rise to slower emergence of novelty.

\section{MATERIALS AND METHODS}

We define biological novelty as the degree of dissimilarity between entities (here pollen assemblages) in a baseline set and their closest counterpart in future target sets (Radeloff et al. 2015). Hence, across-site 'novelty' as defined here is distinct from within-site 'vegetation change' (RoC), because places that change the most are not necessarily the most novel (Radeloff et al. 2015): a similar pollen assemblage may be found at any time in a different region due to range shifts of taxa.

To explore the novelty dynamics relative to past baseline conditions, we use a compilation of $M=772$ pollen records (Fig. 1a) from the European Pollen Database (EPD) (Brewer et al. 2016) with associated age information based on calibrated-age-scale chronologies (cal BP; were 0 cal $\mathrm{BP}=\mathrm{AD}$ 1950) and metadata (Appendix S1). For each record, we extracted pollen counts of the 43 most important terrestrial pollen taxa (Table S1) and collated the counts into $N=31$ consecutive 500-year wide age bins centred on full 500-year intervals between 15000 and 0 cal BP (see Appendix S1). Collated counts were converted to proportions based upon the pollen sum of the 43 terrestrial pollen taxa. Thereafter, all data in each of the 30 age bins from 15000 to 500 cal BP was considered as a data set describing the 'baseline conditions' $\left(S_{O n}\right)$ at a given time in the past $\left(t_{O n}\right.$; with $\left.n=1, \ldots, 30\right)$, and for each baseline system, we built a series of 'target datasets' $\left(\mathrm{S}_{T}=\left\{S_{O n+1}, \ldots, S_{0 n+k}\right\}\right.$; with $\left.k=N-n\right)$ as the sets of all samples from all records for a given time that post-date the baseline. These represent the set of all 'future' systems from that baseline, and allow us to assess novelty in both time and space (Fig. 1b).

We use the chord distance (CD) as a measure for dissimilarity between pollen assemblages (Overpeck et al. 1985; Williams \& Jackson 2007) to estimate within-site RoC and across-site novelty (for results obtained with other dissimilarity coefficients see Appendix S1). RoCs were computed as CD scores within each record between consecutive age bins [between $S_{0 n}$ and $\mathrm{S}_{0 n+1}$; as CD scores $\times\left(500\right.$ years $\left.^{-1}\right)$ ] (Huntley 1990). Across-site novelty was estimated iteratively between each $S_{0 n}$ baseline and each $S_{T}$ target system in the future of $S_{0 n}$ (Fig. 1b). To estimate the degree of novelty, we used the analogue-matching technique (Overpeck et al. 1985), which for each record $i$ in $S_{0 n}$ identifies among all records in the selected $S_{T}$ dataset the record $j$ giving the smallest CD score $\left(C D_{i j, \text { min }}\right.$; i.e. the closest analogue) (Radeloff et al. 2015) (Fig. 1c).

Novelty is a continuous variable, while the categorical differentiation of 'novel' vs. 'non-novel' ecosystems has proven difficult theoretically (Aronson et al. 2014). We focused here on patterns of novelty rather than trying to strictly delineate novel vs. non-novel ecosystems, but used the $n$th percentile of all $C D_{i j, \text { min }}$ scores as a threshold to assess at what point novelty (the $C D_{i j \text {,min }}$ score) is large enough to represent a genuinely novel assemblage (see Appendix S1).

We extracted the geographical coordinates of the records to compute the displacement distance $(\mathrm{km})$ on a geodetic ellipsoid between the location of each record $i$ and its closest counterpart $j$, and divided that by the age difference between $S_{0 n}$ and $S_{T}$ to estimate the average velocity of displacement $\left(\mathrm{km} \mathrm{year}^{-1}\right)$ to the closest analogue in the target set. 


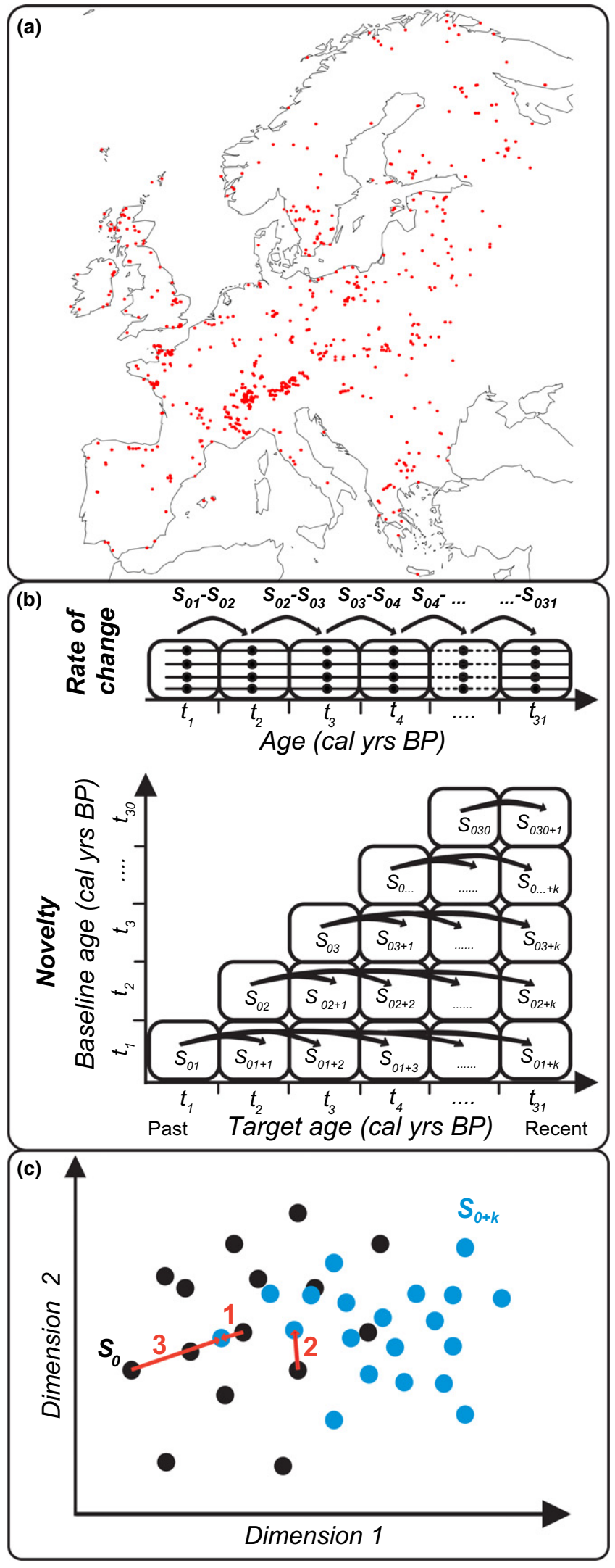

Based on the values obtained above, we calculated median RoC and novelty scores for each $S_{0 n}$ to $S_{0 n+1}$ couplet to detect periods characterized by overall higher within-site
Figure 1 Schematic representation of the theoretical approach used in this study: (a) Spatial distribution of EPD pollen records (red circles) used in this study. (b) A data set $\left(S_{0 n}\right)$ comprizing pollen assemblages that characterize vegetation for a 500-year long snapshot is considered as representing 'average baseline conditions' at time $t_{0 n}$. Rate of vegetation change within sites was calculated as chord distance (CD) between datapoints of the same site in consecutive time slices (i.e. for all $S_{0 n^{-}}$ $S_{0 n+1}$ couplets). To reconstruct the long-term dynamics of novelty emergence, the system $S_{0 n}$ is iteratively compared to each of the 500-year wide 'target systems' $\left(S_{T}=\left\{S_{0 n+1}, \ldots, S_{0 n+k}\right\}\right)$ in its contingent futures (where $S_{0 n+k}$ describes near-to modern conditions, i.e. 0 cal BP). (c) The degree of novelty is quantified as the minimum $\mathrm{CD}$ distance $\left(\mathrm{CD}_{i j, \text { min }}\right)$ between entity $i$ of the baseline set and the closest counterpart $j$ in the target set in a multivariate space. In the example in (c), samples are plotted in a reduced space (axes 1 and 2), black dots indicate entities of $S_{0 n}$, blue dots indicate entities belonging to a target set $S_{0 n+k}$, and red arrows indicate the minimum distance $\left(C D_{i j \text { min }}\right)$ between entities of the two sets. Entities 1-3 experienced increasing degrees of novelty (modified from Radeloff et al. 2015).

RoC and across-site novelty at time lags equal to 500 years from baseline conditions. We binned and differenced the Greenland $\delta^{18} \mathrm{O}$ record (NGRIP Members 2004) to represent large-scale climate changes, and used linear mixed-effect models to explore the responses of RoC and novelty to the climate changes for the time periods before and after 8ka BP (see Appendix S1). We partitioned the within-site and the site-to-site variances to estimate the level of variability in site responses. To illustrate the geographical distribution of $\mathrm{RoC}$ and novelty at lags +500 years, we produced gridded maps of RoC and $C D_{i j, \text { min }}$ values grouped into quartiles for selected baseline ages. Values for grid cells of $50 \times 50 \mathrm{~km}$ were obtained by application of a tricube distance-weighting function with a horizontal search radius of $300 \mathrm{~km}$.

To illustrate the temporal dynamics of novelty emergence for each baseline system $S_{0 n}$, we computed for each set of baseline-to-target couplet $\left(S_{0 n}-S_{T}\right)$ the median degree of novelty $\left(C D_{i j, \text { min }}\right.$ ), the median distance (in $\mathrm{km}$ ) and the median displacement velocity (in $\mathrm{km} \mathrm{year}^{-1}$ ) to the closest analogue. We estimated the rate of novelty change as the difference between median novelty values for consecutive $S_{T}$ systems (as median novelty $\times 500$ years $^{-1}$ ). These variables are arranged in triangular matrices with dimensions of $15 \times 15$ and were represented graphically using heat maps.

All data analyses were carried out using the $\mathrm{R}$ statistical language and associated packages (see Appendix S1).

\section{RESULTS}

Rates of vegetation change and novelty between consecutive time slices

Median RoC scores are highest ( $>0.2)$ during the Bølling, the early-Holocene (from 11500 to $10000 \mathrm{cal} \mathrm{BP}$ ) and the past 1500 years (Fig. 2c), indicating that these are the periods with highest within-site rate of vegetation change. Lowest values are detected when evaluating within-site vegetation change from 12500 to $12000 \mathrm{cal} \mathrm{BP}$ and during the mid-Holocene (9000-5500 cal BP). 


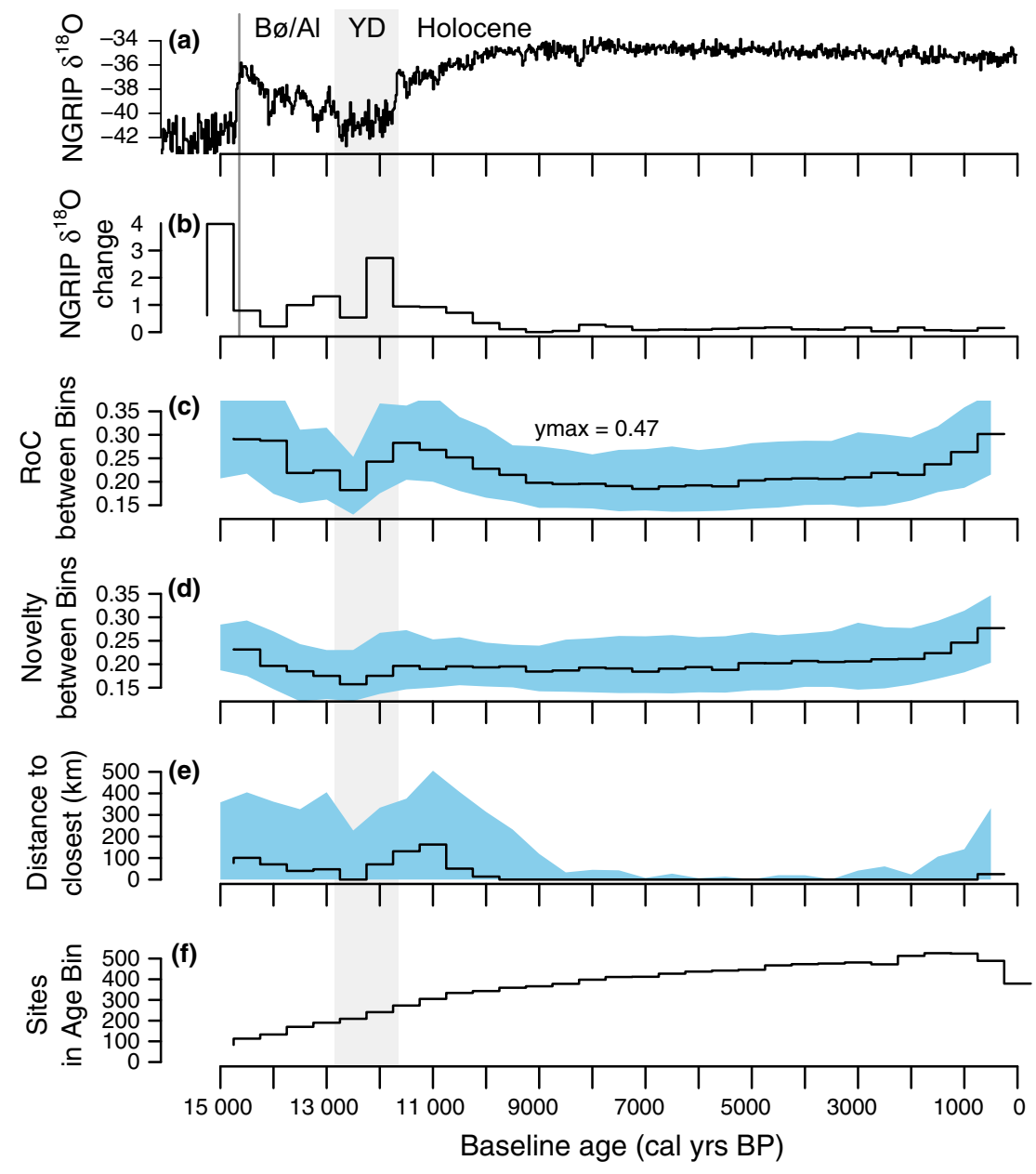

Figure 2 Comparison between (a) Greenland oxygen-isotope $\left(\delta^{18} \mathrm{O}\right)$ record (NGRIP Members 2004) as a template of climate change over Europe [plotted on the GICC05 age scale (Rasmussen et al. 2014)], (b) difference between average of binned $\delta^{18} \mathrm{O}$ values among consecutive age bins as a template of rate of climate change, (c) median rate of vegetation change (RoC) within sites between consecutive age bins (note that $y$-axis was cropped between 0.375 and $0.47 \mathrm{CD}$ ), (d) median degree of novelty across sites between consecutive age bins, (e) geographical distance to the closest analogue in time slice +500 years relative to the baseline conditions, (f) number of records included in each time slice. The blue-shaded areas: range of values between the first and third quartiles within each age bin, and the vertical grey-shaded area marks the Younger Dryas (YD). Bø/Al: Bølling/Allerød.

The closest analogues were allowed to occur in any of the sites of the target dataset, including the same site. This allows a check as to whether the closest analogues occur within the baseline sites. In this case, the RoC and novelty scores would be equivalent, which they are not (Fig. 2). Compared to RoC, the median and the quartile novelty scores are equally elevated for the last 9000 years, while they are lower for the late-glacial, and the early- and late-Holocene indicating that in those periods the baseline assemblages and the closest analogues are not from the same sites. This is confirmed by the geographical distances to the closest analogue (Fig. 2d), which are high during the late-glacial, the early-Holocene, and the late-Holocene. The highest distances to the closest analogue are found for the early-Holocene, while novelty is relatively low for the same period. By contrast, baseline assemblages between 8000 and 2000 cal BP have lowest geographical distances to the closest analogue. Varying site density (Fig. 2f) has no significant effects on the displacement-distance trends (see Appendix S1).

Linear mixed-effect models show significant relationships between climatic changes (differenced NGRIP $\delta^{18} \mathrm{O}$ values) and $\mathrm{RoC}$ and novelty for both pre-8ka and post-8ka periods. However, the relationships are strongest for RoC in the pre$8 \mathrm{ka}$ BP period (see Appendix S1). This can be further seen in the variance components of the models, with a larger amount of variance explained within sites $(c .88 \%)$ for RoC pre-8ka $\mathrm{BP}$, than in the other models (c. 54-67\%), indicating higher spatial variability in RoC response post-8ka BP, and novelty in both periods.

The spatial distribution of RoC and novelty scores (Figs 3 and 4) shows stable vegetation composition in northern Europe vs. continuous change further south for the last 9000 years. Similarities between the two assessments of compositional change are also seen for the Younger Dryas. In contrast, early-Holocene novelty is relatively low in central Europe while RoC values are high.

\section{Long-term emergence of novelty relative to past baseline conditions}

To illustrate the emergence of novelty from the virtual perspective of an observer living in the past, we summarized the 


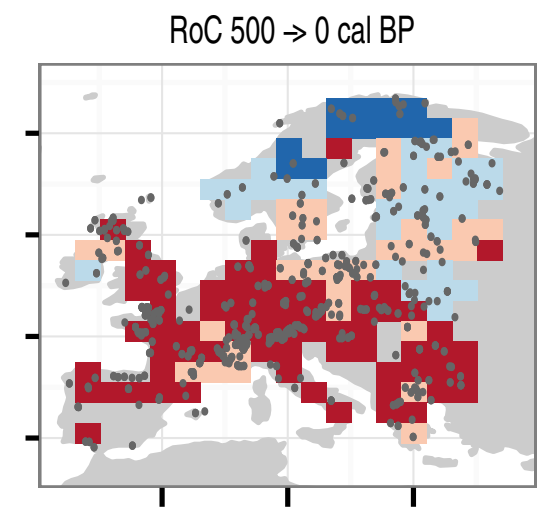

RoC $4500 \rightarrow 4000$ cal BP

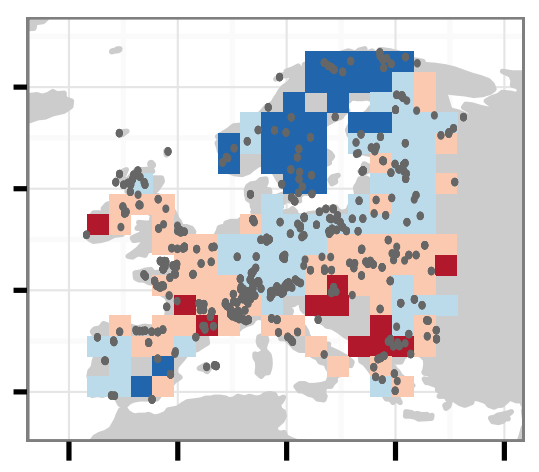

RoC $10500 \rightarrow 10000 \mathrm{cal} \mathrm{BP}$

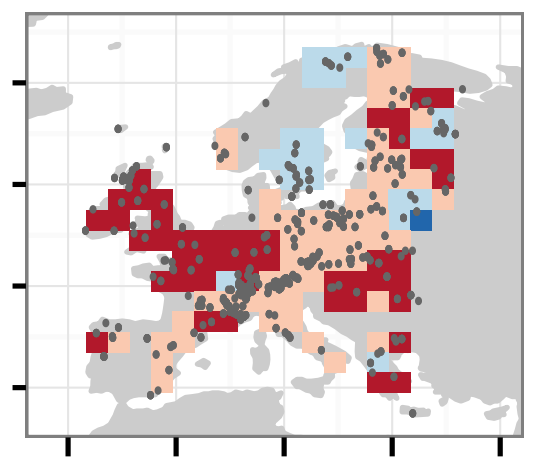

RoC $13500 \rightarrow 13000$ cal BP

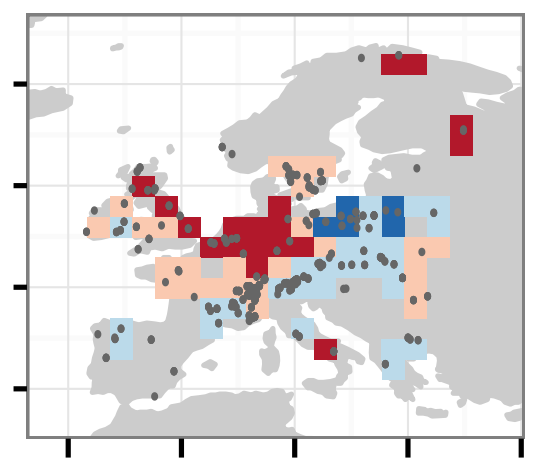

RoC $1000 \rightarrow 500$ cal BP

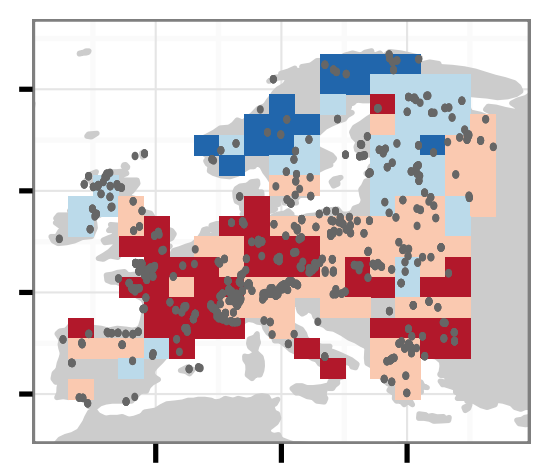

RoC $6500 \rightarrow 6000$ cal BP

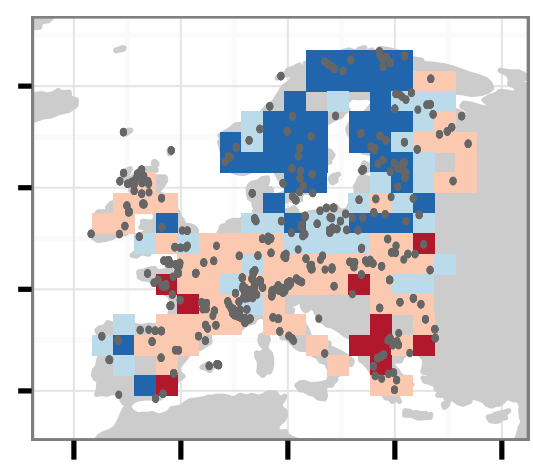

RoC $11500 \rightarrow 11000$ cal BP

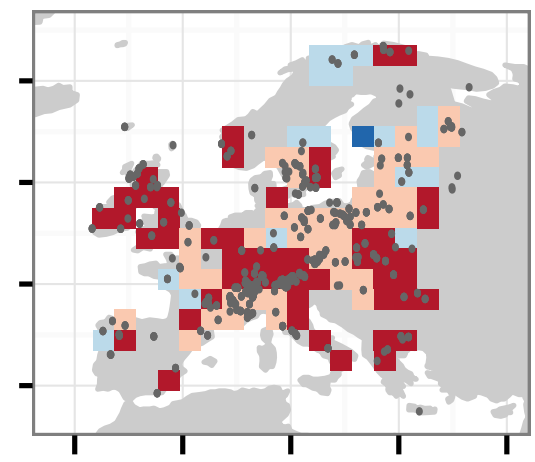

RoC $14000 \rightarrow 13500$ cal BP

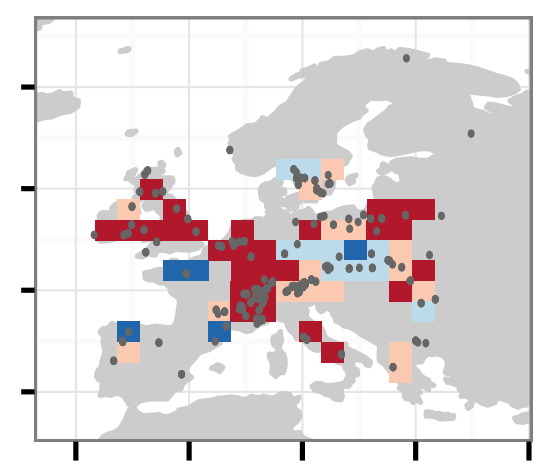

RoC $2500 \rightarrow 2000$ cal BP

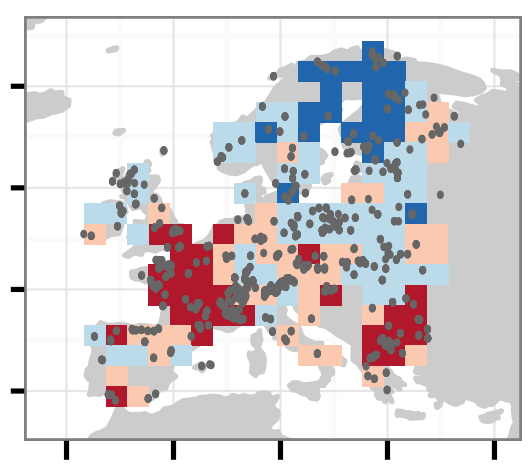

RoC $8500 \rightarrow 8000$ cal BP

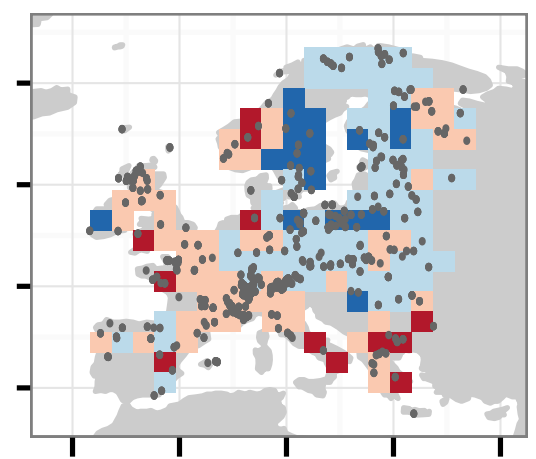

RoC $12500 \rightarrow 12000 \mathrm{cal} \mathrm{BP}$

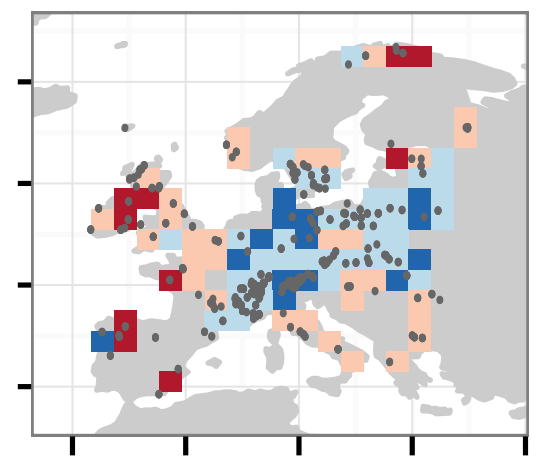

Rate-of-vegetation change (RoC) classes (quartiles)

$0.000567-0.154$

$0.154-0.217$

$0.217-0.308$

$0.308-1.41$

Figure 3 Gridded maps illustrating for selected baseline time slices the spatial patterns of rates of vegetation change (RoC) for consecutive time slices (baseline age $->$ target age). 
Novelty $500 \rightarrow 0$ cal BP

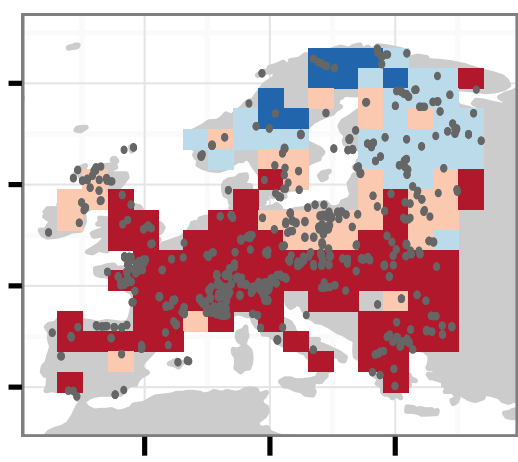

Novelty $4500 \rightarrow 4000$ cal BP

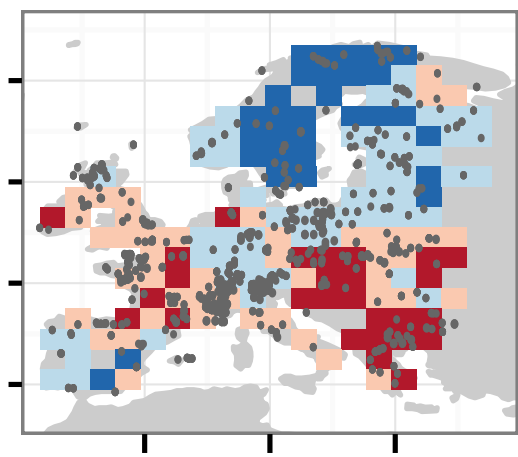

Novelty $10500 \rightarrow 10000$ cal BP

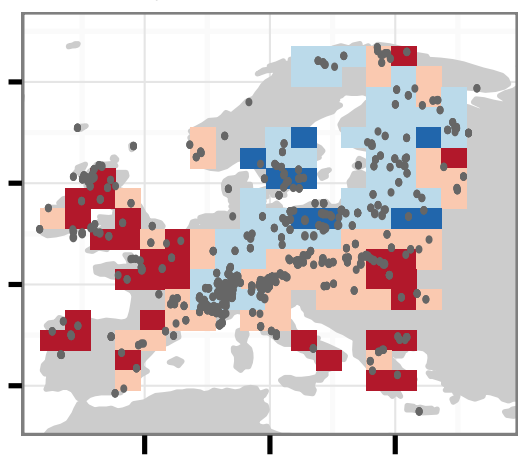

Novelty $13500 \rightarrow 13000$ cal BP

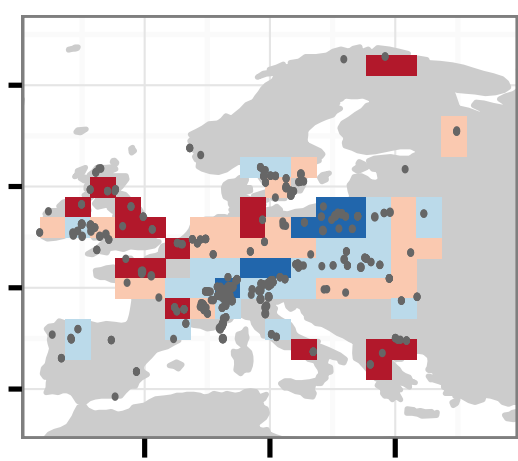

Novelty $1000 \rightarrow 500$ cal BP

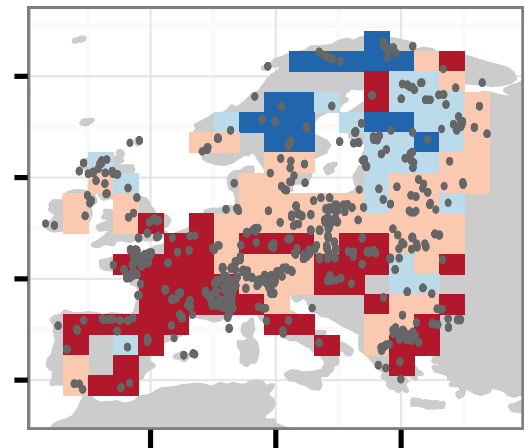

Novelty $6500 \rightarrow 6000$ cal BP

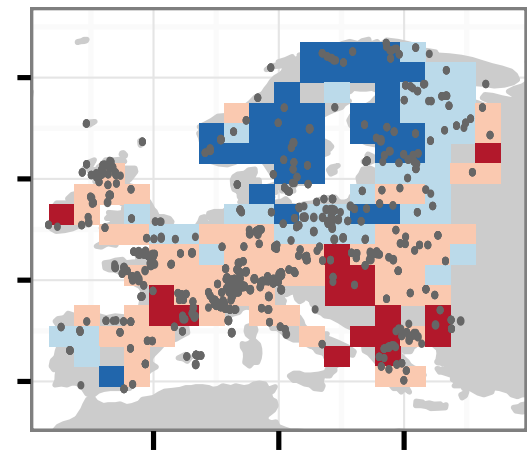

Novelty $11500 \rightarrow 11000$ cal BP

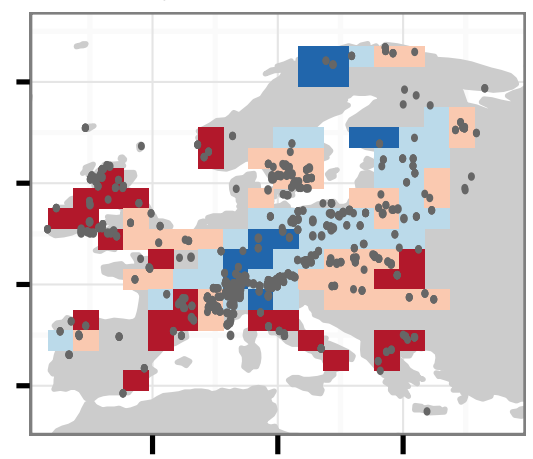

Novelty $14000 \rightarrow 13500$ cal BP

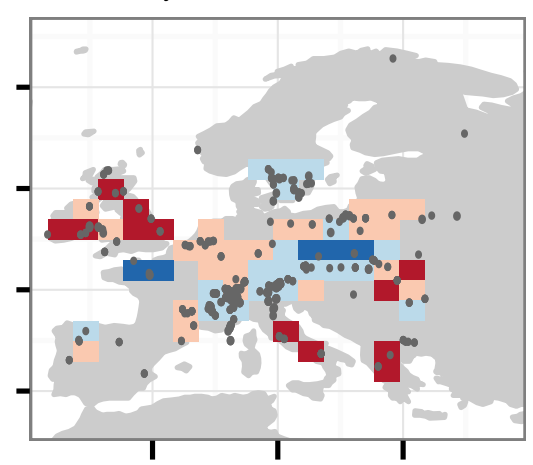

Novelty $2500 \rightarrow 2000$ cal BP

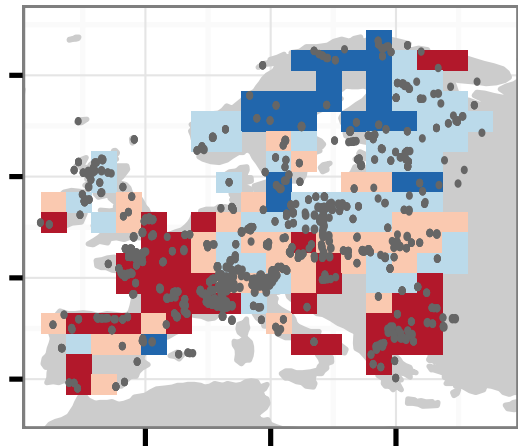

Novelty $8500 \rightarrow 8000$ cal BP

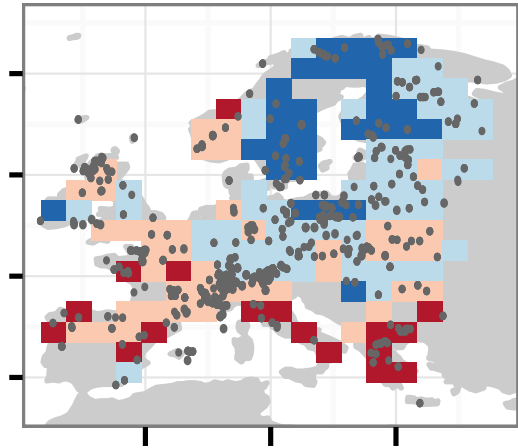

Novelty $12500 \rightarrow 12000$ cal BP

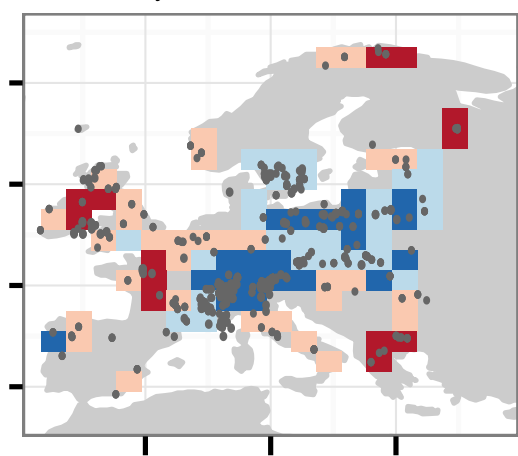

Novelty classes

(quartiles)

$0.00057-0.149$

$0.149-0.202$

$0.202-0.271$

$0.271-0.871$

Figure 4 Gridded maps illustrating for selected baseline time slices the spatial patterns of novelty emergence for consecutive time slices (baseline age -> target age). 

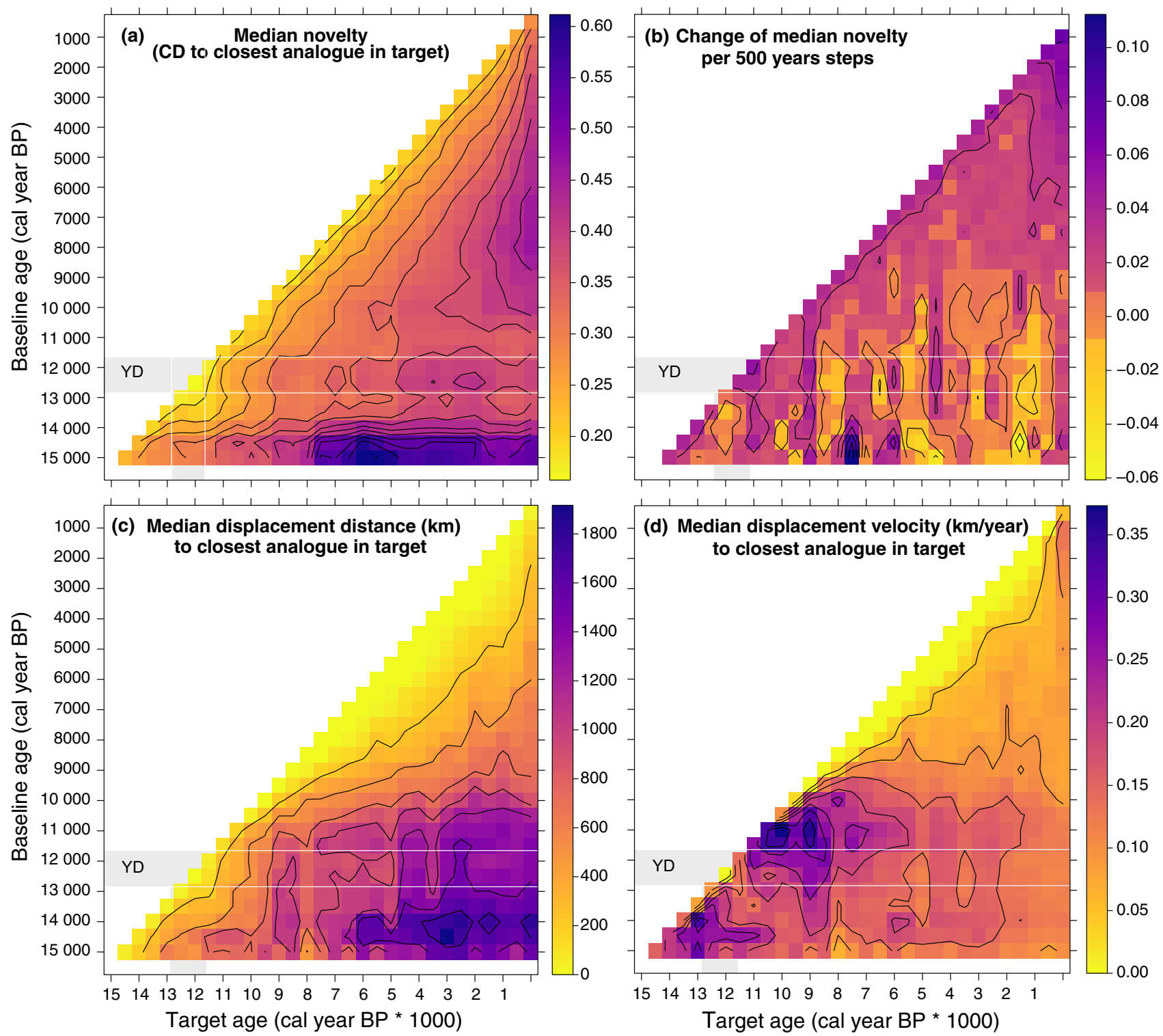

Figure 5 Summary heat maps showing, for each past 'baseline dataset' ( $y$-axis), (a) the median degree of novelty, (b) the change in median novelty per 500 years step (to highlight negligible changes, values around the zero ( $+5 \%$ and $-5 \%$ of the total range) were grouped together), (c) the median displacement distance $(\mathrm{km})$, and $(\mathrm{d})$ the median displacement velocity (as km year $\left.{ }^{-1}\right)$ to the closest counterpart in the 'target dataset' $(x$-axis). Grey-shaded area marks the Younger Dryas (YD).

novelty scores using the median value for each baseline-to-target couplet (Fig. 5a). For every baseline, the development of novelty in its contingent futures can be followed moving along the $x$-axis. Hence, the squares along the diagonal represent the median novelty for a single 500-year time-step from the baseline, as plotted in Fig. 2d.

Median novelty to the nearest counterpart in target bins often increases as time from baseline increases (Fig. 5a). However, for some baselines median novelty decreases, in other words novelty 'cycled backward'. Hence, novelty does not increase as a constant, linear function of time from baseline conditions, and different trajectories can be discerned depending on the composition of baseline pollen assemblages. Contour lines (Fig. 5a), separating median novelty values at equal intervals, are sometimes packed together as a result of steeper increases of median novelty indicating more rapidly reshuffling of communities that were present in the baseline sets. Conversely, when median novelty levels off, contour lines are stretched further apart. For example, early-Holocene baseline landscapes found similarly close counterparts in mid-to-lateHolocene targets, and several late-glacial baselines had more dissimilar counterparts in the mid-Holocene than in late-Holocene targets. These novelty-emergence trends are mirrored by the proportion of sites experiencing a relatively high acrosssite turnover that is broadly comparable to present-day vegetation turnover between biomes (see Appendix S1).

To highlight the changes of novelty through time, Fig. $5 \mathrm{~b}$ shows the rate of novelty change between consecutive target systems. For most baselines younger than $7000 \mathrm{cal}$ BP, median novelty continuously increased and jumped when 
compared to target sets younger than 1000 cal BP. For earlier baselines, the trajectory of novelty development is more variable, including distinct jumps at 11000 and 9000 cal BP, strongest backwards cycling centred around 1000 cal BP, and levelling off or decreasing novelty during the late-Holocene.

The median displacement distance to the closest analogues in target sets (Fig. 5c) generally increases as a function of time and the highest median displacement distances $(>1200 \mathrm{~km})$ are found when considering late-glacial and early-Holocene baselines and late-Holocene targets. Lowest median displacement distances $(<200 \mathrm{~km})$ lasted longer for mid- and lateHolocene baselines than for most late-glacial baselines, and the highest median displacement velocities (ca. $0.3 \mathrm{~km}$ year ${ }^{-1}$ ) are displayed for early-Holocene baselines (Fig. 5d). Varying site density (Fig. 2f) has no influence on the displacementdistance trends (Appendix S1).

Median displacement velocities between closest analogues at the two endpoints of the baseline-target couplets, show opposite long-term trends (Fig. 5d). Long-term velocity decreases for late-glacial and early-Holocene baseline assemblages, indicating that the fastest shifts occurred shortly after baseline conditions, whereas later shifts were slower. By contrast, midand late-Holocene baseline assemblages experienced gradually increasing velocities, because closest analogues were found initially closer to the site. An increase in displacement velocities characterizes all late-Holocene baselines younger than $4000 \mathrm{cal}$ BP when compared to target sets of the past 1000 years, indicating that an acceleration of displacement velocities occurred.

\section{DISCUSSION}

Until now, analyses of novelty emergence have been limited to short time periods from past baselines to the present (Hobbs et al. 2009; Radeloff et al. 2015). Here, we sampled the fossil pollen record over a $c .15 \mathrm{ka}$ time scale to investigate how novelty was related to $\mathrm{RoC}$ at time lags of 500 years, and reconstruct the longer term emergence of novelty in different snapshots of the contingent futures for several baselines in the past. Our results provide new insights into several key aspects of novelty development in relation to environmental changes. We show that (1) the largest rise in $\mathrm{RoC}$ at the beginning of the Holocene was not associated with rising novelty because the spread of plants mitigated the effects of short-term rates of environmental changes on novelty emergence, (2) novelty rose fast with human land-use, and landuse change had a greater effect than post-glacial climatic changes, (3) although novelty generally increases as a function of time, its temporal emergence followed baseline-specific trajectories, and (4) emergence of novelty accelerated due to the contribution of anthropogenic land-cover changes.

We considered the emergence of novelty as a pervasive and continuous process (Radeloff et al. 2015) and avoided categorizing novelty as a binary variable (e.g. 'novel' vs. 'nonnovel'). Nevertheless, using the 75th and 95th percentiles of all $C D_{i j, \text { min }}$ distances for all baselines and all target sets as thresholds to determine the abundance of genuinely novel counterparts (Appendix S1) yields the same patterns as the median degree of novelty (Fig. 5a). Therefore, median novelty is a representative estimate of baseline assemblages experiencing genuinely novel conditions, i.e. shifts in vegetation composition in the order of magnitude of present-day turnover between vegetation types or biomes. Other thresholds would lead to correspondingly larger or more restricted estimates of the area of novel ecosystems, but the spatiotemporal patterns of novelty (Figs 4 and 5) would remain unchanged.

\section{SHORT-TERM EMERGENCE OF NOVELTY IN RELATION TO RATES OF VEGETATION CHANGE}

At the scales considered here, we found a strong association between novelty and RoC, both temporally (Figs $2 \mathrm{~b}$ and c) and spatially (Figs 3 and 4). High rates of environmental changes have been advocated as a potential cause of higher novelty based on the assumptions that (1) favourable climatic conditions may shift across the landscape faster than species disperse into new areas of suitable climate space (Jackson \& Overpeck 2000; Ohlemüller et al. 2006), and that (2) land-use pressure induced habitat transformation, habitat fragmentation and spread of alien invasive species may promote the reshuffling of species into novel ecosystems (Radeloff et al. 2015). While we did not estimate post-glacial velocities of climatic change (Ordonez \& Williams 2013) or anthropogenicinduced rates of environmental change, highest rates of environmental change occurred when RoC scores were high (Fig. 2c): (1) during the late-glacial and the early-Holocene, which were characterized by pronounced and frequent changes in vegetation composition (Birks \& Ammann 2000; Giesecke et al. 2011) and in climatic conditions (Fig. 2b), and (2) during historical times, with the increase in human populations and accompanying land-use (Huntley 1990; Seddon et al. 2015). However, the magnitude of the responses varied, as novelty was generally lower than RoC scores (Fig. 2c and $\mathrm{d}$ and legends to Figs 3 and 4). Based on linear mixed models, climate change is a stronger predictor for within-site variation in $\mathrm{RoC}$, while the novelty response displays a larger betweensite variance (see Appendix S1). These patterns suggest that novelty and RoC may differ in the degree at which they respond to environmental changes, and that across-site novelty varies at a slower pace than the location-specific vegetation changes. The underlying causes of lower novelty might be best illustrated considering the early-Holocene time period, when the association between RoC and novelty was weakest (Fig. 2c and d) and changes in RoC and novelty had a significant positive relationship with $\delta^{18} \mathrm{O}$ changes (see Appendix S1). This period was marked by highest geographical distances to closest analogues (Fig. 2e) and by high rates of spread of early-successional plants, such as Pinus, Betula, Ulmus and Corylus (Feurdean et al. 2013). Therefore, we interpret the low early-Holocene emergence of novelty as the consequence of the rapid post-glacial range shifts of taxa. The vegetation composition changed rapidly at most locations, as shown by the highest within-site variance in the linear mixedeffect models for RoC pre-8ka BP (see Appendix S1). Hence, the high rates of spread meant that replacement by lownovelty counterparts occurred across the landscape, thereby reducing the novelty. This finding is at odds with the assumption that favourable climatic conditions can shift across the 
landscape faster than species disperse into new areas of suitable climate space (Jackson \& Overpeck 2000; Ohlemüller et al. 2006).

It is difficult to say if rates of spread will mitigate the emergence of novelty in the future. Our estimates of early-Holocene median displacement velocities (c. $0.35 \mathrm{~km} \mathrm{year}^{-1}$; Fig. 5e) are consistent with predicted mean climate velocities for the temperate broadleaf and mixed forests biome (Loarie et al. 2009) and with climate-displacement estimates for the past century (Ordonez et al. 2016). However, it is possible that such high rates of spread were limited to the particular environmental conditions encountered during the early-Holocene. At that time, landscapes were fairly open and dominated by early-successional pioneer taxa spreading fast as a result of their life-history strategies (fast growth, large seed production, good dispersal), and greater stress tolerance to large amplitude temperature change and drought (Bhagwat \& Willis 2008). Competition was probably low, and even later-successional taxa with heavy seeds like Quercus reached high rates of spread (Giesecke 2016).

The median novelty for recent target sets exceeds the background of post-glacial novelty (Fig. 2). Over the Middle Ages and the Industrial Revolution, land-cover changes associated with booming human population and agriculture became major determinants for vegetation changes, particularly in Southern and Central Europe (Kaplan et al. 2009; Gaillard et al. 2010). Pasture grassland and arable or disturbed land increased, which led to a decrease in forest cover (Fyfe et al. 2015). Moreover, cultural landscapes became ever more characterized by forest-management practices, and by introduced or cultivated trees for wood and food production (Conedera et al. 2004). The finding of strongest novelty rise for these target sets thus demonstrates that in Europe the effects of landuse were more important than post-glacial climatic changes for the emergence of novelty at a time lag of 500 years.

We found lower novelty, thus more persistent analogy with their future closest counterparts, for late-Holocene Fennoscandian sites than for Central and Southern European sites (Fig. 4). These spatial patterns are at odds with vegetation-modelling results (Reu et al. 2014), which predict higher biological novelty in eastern Scandinavia based only on the effects of abiotic factors. By contrast, our findings are consistent with prior results that inferred lower novelty in Fennoscandia based on the effects of abiotic factors plus human population for historical to modern (AD 1900-2000) and for modern to projected (AD 2000-2050) baseline-to-target couplets (Radeloff et al. 2015). Hence, our results support the view that land-use adds complexity to the modelling of future biological novelty that should be accounted for in analyses of the probability of future effects of climate forcing and land-use change scenarios (Ordonez et al. 2014). Yet, at these short-term time lags, most baseline sites did not encounter genuinely novel assemblages (see Appendix S1).

\section{Long-term emergence of novelty}

To our knowledge, this study is the first to separately analyse the long-term emergence of novelty for a large set of prehistorical and historical baselines. Our data show that novelty often increases as a function of time from the virtual perspective of an observer living in the past (Fig. 5a), and thereby confirms earlier theoretical considerations (Jackson 2006, 2013) that were based on the evidence of the rather recent emergence of some modern ecosystems, and the occurrence in the past of no-modern analogue vegetation assemblages (Overpeck et al. 1992; Jackson \& Williams 2004). However, we found that the emergence of novelty followed different, baseline-specific trajectories (Fig. 5a), confirming the view that it is only meaningful to talk about levels of novelty relative to a specific temporal baseline (Radeloff et al. 2015).

We found that novelty did not develop as a constant, linear function of time from past baseline conditions (Fig. 5b), which would imply a gradually changing world with steadily accumulating changes (Jackson 2013): evidence of novelty jumps occurring several millennia after baselines at times of rapid environmental changes indicate an accelerated reshuffling of vegetation composition across sites. The most distinct of all novelty jumps occurred around 8000 cal BP for Bølling baseline conditions (Fig. 5b). At that time, most of the open pine- and birch-dominated woodlands that characterized the Bølling landscapes of Western and Central Europe had gone. Further, European forest cover was overall at its Holocene maximum, although regional variability accounts for slightly shifted timing of maximum forest cover (Fyfe et al. 2015). In Central Europe, both Fagus and Abies expanded and compositional changes occurred probably in response to shifting climatic modes around $8200 \mathrm{cal}$ BP (Tinner \& Lotter 2006). While this requires further investigation, it offers an example of how terrestrial ecosystems respond to non-linear environmental changes.

Our data indicate that environmental changes related to anthropogenic land-cover changes accelerated the emergence of novelty. Because novelty increased faster during the past millennium relative to baselines younger than $6000 \mathrm{cal}$ BP (Fig. 5b), we interpret the jumps at $1000 \mathrm{cal} \mathrm{BP}$ as the consequence of the rapid emergence of pre-industrial and industrial cultural landscapes (Kaplan et al. 2009; Fyfe et al. 2015). As increasing median displacement velocities to closest analogues are associated with this acceleration (Fig. 5d), it shows that anthropogenic land-cover changes were spatially widespread.

Conversely, we found backwards cycling of novelty (i.e. the transition from high to less novelty) between late-glacial baselines and late-Holocene targets, and a levelling-off of novelty between early-Holocene baselines and late-Holocene targets (Fig. 5a). Jackson (2013) hypothesized the possibility of backwards cycling of novelty with glacial-interglacial cycles, based on the qualitative evidence that last glacial maximum environments and vegetation would have been more similar to those of other glacial maxima than to the interglacial periods. By contrast, because the late-Holocene vegetation composition changes and forest-cover reductions in Europe are mostly attributed to land-use intensification and forest clearance (Henne et al. 2013; Fyfe et al. 2015), our results imply that novelty cycled backwards or levelled-off due to the contribution of land-use changes. Similar observations were made comparing early-Holocene assemblages from Central Italy to modern pollen assemblages (Finsinger et al. 2010). 
The somewhat surprising finding of backwards cycling and of non-increasing novelty from late-glacial and early-Holocene baselines to pre-industrial cultural landscapes may be partly due to the low pollen-taxonomical resolution within herbaceous plant genera, which reduces our ability to distinguish pollen assemblages produced by different species compositions (Jackson \& Williams 2004). An alternative, or additional, explanation is that Europe went from a late-glacial and early-Holocene steppe-dominated continent with groves of trees to a widely deforested landscape with extensive pastures, fields, heaths, maquis, settlements and secondary forests (Birks \& Tinner 2016). The steppe elements became abundant again with the clearance of the forest for agriculture and form today's ruderal flora with only minor additions of archaeophytes that came with the import of seeds from the Near East. As a result, Allerød and earlyHolocene baselines have high analogy (low novelty) to past and modern remnants of the steppe and boreal forests, which persisted in Europe throughout the Holocene and were displaced at increasing distance from the source locations (Fig. 5c).

Under some scenarios, a backwards cycling might be expected to occur in the future. Although Europe is still considered the continent with the smallest fraction of its original forests remaining (Millennium Ecosystem Assessment 2005), forest cover in Europe has increased during the last century due to the abandonment of agropastoral activities in economically marginal areas and the establishment of nature reserves (European Environment Agency 2016). If the current reforestation trend will continue in spite of the growing predicted land-use pressure (Montesino Pouzols et al. 2014), reforested areas may be expected to buffer the rise of future novelty with respect to mid-Holocene baselines. These were characterized by highest forest cover (Fyfe et al. 2015) and are, among all Holocene baselines, the ones showing the highest proportion of between-vegetation-type turnover relative to their closest counterparts in modern cultural landscapes (see Appendix S1).

We found a complex relationship between the post-glacial trajectories of novelty and $\mathrm{RoC}$. Whereas RoC increased at times of rapid climate change and during historical times, the rate of novelty emergence in historical times exceeded the longer term background variability (Figs $2 \mathrm{~d}$ and $5 \mathrm{~b}$ ). The results support the notion that the search for static conservation targets in dynamic environments is likely to be elusive (Radeloff et al. 2015), since landscapes are inherently transitory and the emergence of novelty is inevitable (Williams \& Jackson 2007) on longer term timescales. In addition, they show that unintentional and intentional human action has contributed to a faster rise of novelty earlier than was previously assumed (Radeloff et al. 2015).

Our approach presents an explicitly future-driven perspective of vegetation composition changes through time that provides a valuable long-term perspective on the dynamics and legacies of past ecological systems, which may help bridging the gap between palaeoecology and ecology (Willis \& Birks 2006). Further evaluation of our results should be done through comparison with vegetation and climate models.

\section{ACKNOWLEDGEMENTS}

We thank Gavin Simpson and two anonymous reviewers for their thoughtful comments. Pollen data were extracted from the European Pollen Database (EPD; http://www.europeanpol lendatabase.net/), and the work of the data contributors and the EPD community is gratefully acknowledged.

\section{AUTHORSHIP}

WF, TG and SB designed the experiments; ML compiled the data, WF developed and performed the RoC and novelty analyses, and the gridded maps; SB developed and performed the linear mixed-effect models. All authors analysed the results and contributed to writing the manuscript.

\section{DATA ACCESSIBILITY STATEMENT}

Data and $\mathrm{R}$ scripts to replicate all the calculations for results presented in the paper are available from the Dryad Digital Repository: https://doi.org/10.5061/dryad.cg250.

\section{REFERENCES}

Aronson, J., Murcia, C., Kattan, G.H., Moreno-Mateos, D., Dixon, K. \& Simberloff, D. (2014). The road to confusion is paved with novel ecosystem labels: a reply to Hobbs et al.. Trends Ecol. Evol., 29, 646647.

Bhagwat, S.A. \& Willis, K.J. (2008). Species persistence in northerly glacial refugia of Europe: a matter of chance or biogeographical traits? J. Biogeogr., 35, 464-482.

Birks, H.H. \& Ammann, B. (2000). Two terrestrial records of rapid climatic change during the glacial-Holocene transition (14,000-9,000 calendar years BP) from Europe. Proc. Natl Acad. Sci. USA, 97, 13901394.

Birks, H.J.B. \& Tinner, W. (2016). Past forests of Europe. In: European Atlas of Forest Tree Species (eds San-Miguel-Ayanz, J., De Rigo, D., Caudullo, G., Houston Durrant, T. \& Mauri, A.). Publications Office of the European Union, Luxembourg, pp. 36-39.

Bradshaw, R.H.W. \& Lindbladh, M. (2005). Regional spread and standscale establishment of Fagus sylvatica and Picea abies in Scandinavia. Ecology, 86, 1679-1686.

Brewer, S., Giesecke, T., Davis, B.A.S., Finsinger, W., Wolters, S., Binney, H. et al. (2016). Late-glacial and Holocene European pollen data. J. Maps, in press, doi: 10.1080/17445647.2016.1197613

Bush, M.B., De Oliveira, P.E., Colinvaux, P.A., Miller, M.C. \& Moreno, J.E. (2004). Amazonian paleoecological histories: One hill, three watersheds. Palaeogeogr. Palaeoclimatol. Palaeoecol., 214, 359-393.

Conedera, M., Krebs, P., Tinner, W., Pradella, M. \& Torriani, D. (2004). The cultivation of Castanea sativa (Mill.) in Europe, from its origin to its diffusion on a continental scale. Veg. Hist. Archaeobotany, 13, 161-179.

Davis, M.B. (1981). Quaternary history and the stability of forest communities. In: Forest Succession: Concepts and Application (eds West, D.C., Shugart, H.H. \& Botkin, D.B.). Springer Verlag, New York, pp. 132-154

Diffenbaugh, N.S. \& Field, C.B. (2013). Changes in ecologically critical terrestrial climate conditions. Science, 341, 486-492.

European Environment Agency. (2016). European Forest Ecosystems State and Trends. Publications Office of the European Union, Luxembourg

Feurdean, A., Bhagwat, S.A., Willis, K.J., Birks, H.J.B., Lischke, H. \& Hickler, T. (2013). Tree Migration-Rates: Narrowing the Gap between Inferred Post-Glacial Rates and Projected Rates. PLoS ONE, 8, e71797. 
Finsinger, W., Colombaroli, D., de Beaulieu, J.-L., Valsecchi, V., Vannière, B., Vescovi, E. et al. (2010). Early to mid-Holocene climate change at Lago dell'Accesa (central Italy): Climate signal or anthropogenic bias? J. Quat. Sci., 25, 1239-1247.

Fyfe, R.M., Woodbridge, J. \& Roberts, N. (2015). From forest to farmland: pollen-inferred land cover change across Europe using the pseudobiomization approach. Glob. Change Biol., 21, 1197-1212.

Gaillard, M.-J., Sugita, S., Mazier, F., Trondman, A.-K., Broström, A., Hickler, T. et al. (2010). Holocene land-cover reconstructions for studies on land cover-climate feedbacks. Clim. Past, 6, 483-499.

Giesecke, T. (2016). Did thermophilous trees spread into central Europe during the Lateglacial? New Phytol., 212, 15-18.

Giesecke, T., Bennett, K.D., Birks, H.J.B., Bozilova, E., Feurdean, A., Finsinger, W. et al. (2011). The pace of Holocene vegetation change synchronous developments versus chance. Quat. Sci. Rev., 30, 2805-2814.

Gleason, H.A. (1939). The individualistic concept of the plant association. Am. Midl. Nat., 21, 92-110.

Henne, P.D., Elkin, C., Colombaroli, D., Samartin, S., Bugmann, H., Heiri, O. et al. (2013). Impacts of changing climate and land use on vegetation dynamics in a Mediterranean ecosystem: insights from paleoecology and dynamic modeling. Landsc. Ecol., 28, 819-833.

Hobbs, R.J., Higgs, E. \& Harris, J.A. (2009). Novel ecosystems: implications for conservation and restoration. Trends Ecol. Evol., 24, 599-605.

Hobbs, R.J., Higgs, E., Hall, C.M., Bridgewater, P., Chapin, F.S., Ellis, E.C. et al. (2014). Managing the whole landscape: historical, hybrid, and novel ecosystems. Front. Ecol. Environ., 12, 557-564.

Huntley, B. (1990). Dissimilarity mapping between fossil and contemporary pollen spectra in Europe for the past 13,000 years. Quat. Res., 33, 360-376.

Huntley, B. \& Birks, H.J.B. (1983). An Atlas of Past and Present Pollen Maps for Europe: 0-13,000-Years Ago. Cambridge University Press, Cambridge

Jackson, S.T. (2006). Vegetation, environment, and time: the origination and termination of ecosystems. J. Veg. Sci., 17, 549-557.

Jackson, S.T. (2013). Perspective: Ecological Novelty is not New. In: Novel Ecosystems: Intervening in the New Ecological World Order (eds Hobbs, R.J., Higgs, E.S. \& Hall, C.M.). John Wiley \& Sons Ltd., Chichester, UK, p. 61-65. doi: 10.1002/9781118354186.ch7

Jackson, S.T. \& Overpeck, J.T. (2000). Responses of plant populations and communities to environmental changes of the late Quaternary. Paleobiology, 26, 194-220.

Jackson, S.T. \& Williams, J.W. (2004). Modern analogs in Quaternary paleoecology: here Today, Gone Yesterday, Gone Tomorrow? Аnnu. Rev. Earth Planet. Sci., 32, 495-537.

Joos, F. \& Spahni, R. (2008). Rates of change in natural and anthropogenic radiative forcing over the past 20,000 years. Proc. Natl Acad. Sci., 105, 1425-1430. doi:10.1073/pnas.0707386105

Kaplan, J.O., Krumhardt, K.M. \& Zimmermann, N. (2009). The prehistoric and preindustrial deforestation of Europe. Quat. Sci. Rev., $28,3016-3034$

Loarie, S.R., Duffy, P.B., Hamilton, H., Asner, G.P., Field, C.B. \& Ackerly, D.D. (2009). The velocity of climate change. Nature, 462, 1052-1055.

Matthews, J.A. (1996). Classics in physical geography revisited. Prog. Phys. Geogr., 20, 193-203.

Millennium Ecosystem Assessment. (2005). Ecosystems and Human Wellbeing: Synthesis. Island Press, Washington, DC

Montesino Pouzols, F., Toivonen, T., Di Minin, E., Kukkala, A.S., Kullberg, P., Kuusterä, J. et al. (2014). Global protected area expansion is compromised by projected land-use and parochialism. Nature, 516, 383-386.

NGRIP Members. (2004). High-resolution record of Northern Hemisphere climate extending into the last interglacial period. Nature, 431, 147-151; doi:10.1038/nature02805.

Ohlemüller, R., Gritti, E.S., Sykes, M.T. \& Thomas, C.D. (2006). Towards European climate risk surfaces: the extent and distribution of analogous and non-analogous climates 1931-2100. Glob. Ecol. Biogeogr., 15, 395-405.

Ordonez, A. \& Williams, J.W. (2013). Climatic and biotic velocities for woody taxa distributions over the last 16000 years in eastern North America. Ecol. Lett., 16, 773-781.

Ordonez, A., Martinuzzi, S., Radeloff, V.C. \& Williams, J.W. (2014). Combined speeds of climate and land-use change of the conterminous US until 2050. Nat. Clim. Change, 4, 811-816.

Ordonez, A., Williams, J.W. \& Svenning, J.-C. (2016). Mapping climatic mechanisms likely to favour the emergence of novel communities. Nat. Clim. Change, 1, 1-1.

Overpeck, J.T., Webb, I. \& Prentice, I.C. (1985). Quantitative interpretation of fossil pollen spectra: dissimilarity coefficients and the method of modern analogs. Quat. Res., 23, 87-108.

Overpeck, J., Webb, R.S. \& Webb, T. III (1992). Mapping eastern North American vegetation change of the past $18 \mathrm{ka}$ : no-analogs and the future. Geology, 20, 1071-1074.

Radeloff, V.C., Williams, J.W., Bateman, B.L., Burke, K.D., Carter, S.K., Childress, E.S. et al. (2015). The rise of novelty in ecosystems. Ecol. Appl., 25, 2051-2068.

Rasmussen, S.O., Bigler, M., Blockley, S.P., Blunier, T., Buchardt, S.L., Clausen, H.B. et al. (2014). A stratigraphic framework for abrupt climatic changes during the Last Glacial period based on three synchronized Greenland ice-core records: refining and extending the INTIMATE event stratigraphy. Quat. Sci. Rev., 106, 14-28.

Reu, B., Zaehle, S., Bohn, K., Pavlick, R., Schmidtlein, S., Williams, J.W. et al. (2014). Future no-analogue vegetation produced by no-analogue combinations of temperature and insolation: no-analogue vegetation, temperature and insolation. Glob. Ecol. Biogeogr., 23, 156-167.

Seddon, A.W., Macias-Fauria, M. \& Willis, K.J. (2015). Climate and abrupt vegetation change in Northern Europe since the last deglaciation. Holocene, 25, 25-36.

Tinner, W. \& Lotter, A.F. (2006). Holocene expansions of Fagus silvatica and Abies alba in Central Europe: where are we after eight decades of debate? Quat. Sci. Rev., 25, 526-549.

Tinner, W., Colombaroli, D., Heiri, O., Henne, P.D., Steinacher, M., Untenecker, J. et al. (2013). The past ecology of Abies alba provides new perspectives on future responses of silver fir forests to global warming. Ecol. Monogr., 83, 419-439.

Williams, J.W. \& Jackson, S.T. (2007). Novel climates, no-analog communities, and ecological surprises. Front. Ecol. Environ., 5, 475-482.

Williams, J.W., Post, D.M., Cwynar, L.C., Lotter, A.F. \& Levesque, A.J. (2002). Rapid and widespread vegetation responses to past climate change in the North Atlantic region. Geology, 30, 971-974.

Williams, J.W., Kharouba, H.M., Veloz, S., Vellend, M., McLachlan, J., Liu, Z. et al. (2013). The ice age ecologist: testing methods for reserve prioritization during the last global warming: reserve selection and the ice age ecologist. Glob. Ecol. Biogeogr., 22, 289-301.

Willis, K.J. \& Birks, H.J.B. (2006). What is natural? The need for a longterm perspective in biodiversity conservation Science, 314, 1261-1265. 